Athens Journal of Business \& Economics -

Volume 8, Issue 2, April 2022 -Pages 119-138

\title{
Rural Structural Transformation and Agricultural Productivity in Nigeria
}

\begin{abstract}
By Abidemi Abiola* \& Rasak A. Adefabi ${ }^{ \pm}$
Rural structural transformation is best defined as structural changes in the rural areas occasioned by government policies and programmes with the intention of altering the contributions of major sector of the economy for the enhancement of agricultural sector. The study aimed at investigating the impact of rural structural transformation on agricultural productivity in Nigeria. The methodology adopted for the study was Structural Autoregression (SVAR). Six variables of expenditure on education (EXPE), expenditure on health (EXPH), expenditure on electricity (EXPEL), expenditure on telecommunication (EXPTC), expenditure on roads and construction (EXPRC) and expenditure on agriculture (EXPA). Of the six explanatory variables only expenditure on agriculture was found to be negatively related to agricultural productivity, while the others were positively related to it. Several reasons of which of official corruption by the handlers of agricultural funds could possibly be one of the reasons for the negative relationship between expenditure on agriculture and agricultural productivity. Among many other recommendations was the need to provide clinics and health centres to the rural areas, provision of good and accessible roads, provision of electricity and internet facilities. This will act as motivating factors in curbing rural-urban migration, and by extension improve the lots of agricultural productivity in Nigeria.
\end{abstract}

Keywords: rural, structural transformation, agricultural productivity, agricultural policies and structural VAR

\section{Introduction}

That agriculture is about most important sector in any given economy is to over-emphasise the obvious. Even with the best of the industrialised economy, agricultural sector cannot be regarded as secondary (Alvarez-Cuadrado and Poschke 2009). It is always at the front burner of national discourse. In most economies and especially the developing economies, agriculture is chief employer of labour. In Nigeria with the entire Dutch disease syndrome that saw many employees moving from agricultural sector to the manufacturing, industrial and oil sector, the sector still remains the largest employer of labour, accounting for about $70 \%$ of the labour force (World Bank 2018). The sector's contribution to food production, the most fundamental of human wants, the production of raw materials for many industries, contribution to the nation's gross domestic product, provision

*Senior Lecturer, Department of Economics, Ajayi Crowther University, Nigeria.

${ }^{ \pm}$Chief Lecturer, Department of Economics, Emmanuel Alayande College of Education, Nigeria.

https://doi.org/10.30958/ajbe.8-2-2

doi=10.30958/ajbe. $8-2-2$ 
of jobs as means of livelihood of many are pointers to the importance of the sector to the economy.

The sector is an umbrella body for four other subsectors of crop production, animal husbandry (livestock), fishery and forestry. While not demeaning the importance of the other three subsectors, the contribution of the crop production must be emphasized as the subsector is the largest contributor to the nation's gross domestic product, accounting for $88 \%$ in the last quarter of 2016 (CBN 2018). According to Adikwu (2016), about $70 \%$ of the crop production is done at the rural areas where farmers lived in penury, thatched houses in squalid state, and lack basic amenities such as quality health care, electricity, portable water and inaccessible roads. Farmers in most of these developing economies are largely subsistence, depend on rain for irrigation, use simple crude tools for production which deny them the opportunity for large scale production. Compounding these problems for those who still manage to produce under these strenuous conditions is the little or no access to markets on account of poor conditions of the roads. The effect of which is the acceptance of peanuts as factor payments to the farmers for participating in the production process. A further effect of which is that all most all the rural areas are populated by aged population who are constrained on account of age to remain at the areas while the active youths that are capable of enhancing agricultural productivity migrate to the urban centres in search of greener pastures.

For reasons of general to specific, debate and topical issues on the importance of agricultural sector will continue unabated now and in the nearest future (Gangopadhyay and Mondal 2017). From the structural change Lewis theory of development (Todaro and Smith 2009), the importance of agricultural sector to national development in a developing economy with surplus labour in the traditional agricultural sector existing side by side with high-productivity modern urban industrial sector has long been noticed. The African Union Comprehensive African Agriculture Development Programme (CAADP) that advises governments in Africa countries to earmark $10 \%$ of their annual budget to agriculture, also underscore the importance of agricultural sector. The CAADP is a growth-oriented agricultural development agenda, aimed at increasing agriculture growth rates to a minimum of $6 \%$ per year to create the wealth needed for rural communities and households in Africa to prosper (Adeyinka et al. 2013). In the Nigerian context, programmes and policies have been put in place by successful governments to better the lots of agricultural sector in the country. The Farm Settlement Programme (FSP) introduced by the Western government in 1959, the National Accelerated Food Production Programme (NAFPP) initiated in 1972, the Agricultural Development Programme (ADPs) established by the Northern state governments in 1974, the Operation Feed the Nation (OFN) of 1976, the River Basin Development Authorities (RBDA) of 1976, the Green Revolution (GR) of 1980, the Directorate of Food Road and Rural Infrastructure (DFRRI) of 1986 have all at one time or the other established to address the myriad of problems facing agricultural sector.

The failure or not too felt impact of these programmes is not unconnected with the lip service implementation methods of those programmes. This is coupled with the fact that attention has been shifted to the money spinning oil sector in the 
country since the discovery of oil in commercial quantity in the late 60s. Efforts at revamping the agricultural sector according to (Ogbe 2018) however became more prominent the last decade in the country beginning from the Agricultural Transformation Agenda (2011) of Jonathan administration, the Economic Recovery and Growth Plan (2017-2020) of Buhari administration that encompasses Agricultural Promotion Policy (APP) alternatively called the "Green Alternative" (2016-2020) and Agricultural Sector Food Security and Nutrition Strategy (20162025).

\section{Statement of the Problem}

As observed in the previous section, a lot of programmes and policies have been put in place to revamp agricultural sector in Nigeria. The reasons for revamping according to Abiola (2017) stem from the apparent manifestation of the danger in monocultural nature of a given economy. The warning from oil experts on the possible exhaustion of oil deposits in the country in the nearest future and of course the increasing need for the nation to diversify her economy. From general macroeconomic policies to agricultural specific policies and programmes, efforts at concentrating on agricultural sector have gathered momentum in the recent past. These policies and programmes however have not produced the much desired results in terms of food sufficiency, adequate agricultural productivity to meet local consumption talkless of export.

According to World Bank (2018), the country's agricultural export's earning was $\$ 1,116,083.44$ as against import's payment of $\$ 2,554,896.19$. This staggering difference between the export and import is a major indication of the failure of the policies and programmes in achieving the expected agricultural output results (Yakubu and Akanegbu 2015). One striking feature of the country's agricultural import according to Food and Agricultural Organisation (FAO) (2011) is that a larger percentage of the country's agricultural import is on food. Nigeria's total food and agricultural imports are growing and estimated at more than $\$ 10$ billion in 2015. Wheat, rice, brown sugar, frozen fish, dairy products, vegetable oil, intermediate and consumer-oriented products are the largest imports. By continent, Nigeria imported goods mostly from Asia (44.6 percent), EU (33.6 percent), Americas (14.1), Africa (6.5 percent), and others (1.2 percent). By country, Nigeria's most significant suppliers include China (23 percent), United States (10 percent), India ( 8 percent), Belgium (6 percent), Netherlands (6 percent), and others countries across the world ${ }^{1}$.

The questions that arose are despite trade policies like imports substitution strategy for production of more rice in the country, quota ban on rice importation, exchange rate restrictions that affect the importation of wheat, establishment of bank of agriculture to facilitate accessibility of local farmers to credit facilities, a lot of agricultural programmes like the FADAMA I, II and III, all for the purpose of boosting agricultural productivity in the country, why is the country still not

${ }^{1}$ USDA 2016. Retrieved from: www.fas.usda.gov/data/world-agricultural-production. [Accessed 8 February 2021] 
sufficient in food production, general agricultural productivity and value addition to agriculture. While the answer to the question could be viewed from far and remote causes, the glaring immediate cause could be traced to the state of most rural areas in the country as well as the mode of operations of agricultural services. Why are there no social amenities like good roads, electricity, pipe borne water, hospitals and clinics, recreation facilities, internet facilities, etc., in the rural areas. Is there any impact these amenities have on the performance of agricultural productivity? Is there any link between the absence of these amenities and the absence of young able bodied men to engage in agricultural production in the rural areas? What of the orthodox method of agricultural production that is archaic as far as modern method of farm practices are concerned? What programmes and policies are in place to transform the entire structure of rural settings to make agriculture more attractive to teeming unemployed people? These and many more questions form the basis of the research study. The broad objective of the study therefore is to investigate the impact of rural structural transformation on agricultural productivity in Nigeria. Specifically the study will examine the present rural structure vis-à-vis the present agricultural productivity, as well as investigating the possible effects of increasing funding to agricultural sector on agricultural productivity in Nigeria.

\section{Literature Review}

Structural transformation according to Eboh (2014) connotes progressive decline in the share of primary production (agriculture and minerals) in national output as the economy modernises and grows, while manufacturing and services sectors grow increasingly. Another correlate of structural transformation is the reallocation of the labour force through specialisation (in products and skills) and market differentiation (Kendrick 1977). Specialisation and technological change are the driving forces that transform an agrarian economy into a diversified economy. Structural change is caused by changes in consumer demand and varied increases in productivity in the different sectors of the economy, due to specialisation and division of labour associated with scientific and industrial advances (Timmer and Akkus 2008).

Conceptually, a distinction between two closely related terms of structural transformation (ST) and rural transformation (RT) is imperative for analytical purpose. According to Omamo et al. (2016), structural transformation reflects changes in the relative contributions of agriculture, services, and manufacturing in an economy, while rural transformation (RT) is defined as a process of change in rural areas, which depends on many factors and dynamics. Rural transformation is embedded within structural transformation, as rural people change their occupations, invest, diversify livelihoods, and relate differently to each other within their families, communities, and social institutions (Losch et al. 2012). In semantic parlance therefore, rural structural transformation is seen as structural changes in the rural areas occasioned by government policies and programmes 
with the intention of altering the contributions of major sector of the economy in favour of agricultural sector (Naseem et al. 2107).

Diao (2010) examines the success story of Ghana in terms of steady economic growth and poverty reduction and the likelihood of Ghana moving in the direction of most Asian countries that placed less premium on agriculture over and above other sectors of the economy. The study adopted a dynamic Computable General Equilibrium model with a view of examining which of the sectors of Ghanian economy will achieve a faster increase in national income and poverty reduction. The forward looking analysis of the dynamic CGE model shows that, even with much higher growth in the non-agricultural sector, agriculture will continue to be an important sector in terms of its size in the economy. Rapid growth in the manufacturing and export services can only occur when these sectors significantly improve their international competitiveness. However, with high dependency on imports for manufacturing, such growth also implies to lower prices for manufacturing goods produced domestically, which leads to lower the share of this sector in total GDP. Domestically oriented industry (e.g., construction) and services can only grow with income growth for a majority of households and rapid urbanization. Hence, rapid growth in non-traded industry and services is rather an outcome of broad-based growth, including growth in agriculture, and it will be unlikely to become a main driver to lead the economy wide growth. Moreover, the initial conditions of the structures and competition capacity of industry and services indicate that Ghana will unlikely become an African "Tiger" in next 10 years and will unlikely to observe rapid structural change in its economy. Agriculture will continue to be an important and big economic sector even when Ghana manages to become a middle income country in the next 10 years.

The study of Briones and Felipe (2013) is on Asia. The paper exposes that relative to other developing regions, developing Asia has experienced a slower decline in employment share in agriculture, compared to its output share; a rapid growth in labor and land productivity; and a shift from agricultural output from traditional to high-value products. The most successful Asian economies have pursued an agricultural development-led industrialization pathway. Nevertheless, agriculture remains the largest employer in many large Asian countries, hence future structural transformation must take into account agricultural transformation. Extrapolating from past trends, and taking to account emerging conditions, many countries of developing Asia will be expected to move on to the next phase of agricultural development; however even in the long term, agriculture's employment share will continue to be sizable relative with the output share. The paper concludes among others that to expedite transformation, many Asian countries will still need to promote long term productivity growth in agriculture and facilitate upgrading of their farms and agroenterprises within the global value chain.

The central theme of Lopes (2015) was on the imperativeness of agriculture as part of Africa's structural transformation. The paper buttresses its position with evidence that suggests that countries that have increased productivity across the globe benefited from economic growth sustained by agricultural transformation. Africans have an opportunity, now more than at any time before, to change their lives through increased agricultural productivity and enhanced agribusiness that 
connects smallholders to national, regional and global value chains. Food security has been given rightful prominence in the debate but cannot be a replacement for real transformation. It is important to renew the building blocks that are necessary for a deeper discussion of the connection to be made between agriculture and industrialisation. This paper proposes a six-point strategy to address major obstacles hampering African agricultural transformation. These include among others; the need to re-emphasise strategies and policies aimed at structural transformation; and the need to reduce the vulnerability of millions of African small scale farmers to high, volatile prices while increasing resilience to shocks. Oboh and Adeleke (2016) were on inclusive agricultural growth in Nigeria. The paper observed that agriculture has been identified as a critical sector with huge potential for promoting inclusive growth by stimulating economic growth, reducing poverty, and creating employment for a large number of people in developing countries. Against this backdrop, the paper assessed the sector's potential in accelerating sustainable broad-based growth and examined key strategies for realizing inclusive agricultural growth in Nigeria. Using data, covering 1981-2015, the results indicate agriculture's significant contribution to economic growth which is a necessary (but not sufficient) condition for achieving inclusive growth. Results of employment elasticity computed for the three major sectors suggested that agriculture led others (1.88) followed by services sector (1.18) and industry (0.33) in contributing to employment. Based on the analysis, the paper recommended policies such as increased public investment, access to farm inputs, youth-friendly and price stabilization programmes in order to accelerate inclusive growth in the agriculture sector.

Omamo et al. (2016) extended their work beyond the shores of Nigeria as the paper takes a look at the structural transformation of agriculture in Africa. The paper is of the opinion that any successful long-term structural transformation will start from agriculture and move through services and then to a more diversified manufacturing sector, thereafter reverting to expansion of highly skilled services. It also observed that comprehensive rural transformation in agriculturally dependent countries is constrained when not led by technical dynamism. With few exceptions, such dynamism is weak in African agriculture despite recent acceleration. In addition, mobility of factors (especially land) among alternative uses constrains rural transformation. Using descriptive analysis, the paper offer suggestions which include: public policy and investment must focus on two elements: leveraging burgeoning demand emanating from urbanization and dietary diversification to deepen employment in the rural nonfarm economy, and developing inclusive food supply chains to provision ever-increasing numbers of consumers. Rural suppliers need to sell to sources of dynamic, growing demand, especially to domestic urban markets. Broad objectives and priorities for policy and investment include improving market performance and meeting new demands, enhancing access to land and tenure security for smallholders and investors, financing agribusiness, upgrading infrastructure, using public-private partnerships where possible, building skills and entrepreneurship, particularly among young people, and making agribusiness inclusive by integrating market-oriented smallholders and rural communities into dynamic value chains. 
Barrett et al. (2017) are more of the extension of Omamo et al. (2016). The paper pointed out that from 2000 to 2014, per capita GDP in sub-Saharan Africa increased by almost $35 \%$ in real terms, doubling in some countries. The irony of such progress is that agricultural productivity growth remained low in the aggregate, despite some bright spots, and poverty reduction has been steady but discouragingly slow. This paper argues that ending extreme poverty will require structural change in agriculture and in rural African economies more broadly. Drawing on a range of recent research, this paper outlines broad priority areas for policy actions to accelerate productivity and initiate structural change in the agriculture sector and the rural non-farm economy.

Nwankpa (2017) paper examines the agricultural transformation via-a-vis hunger and poverty eradication as a means of sustaining economic growth and development in Nigeria. The paper tries to highlight the importance of agricultural sector in terms of its contribution to the means of livelihood of a larger percentage of Nigeria and in terms of its contribution to the country's economic growth. The study went on to discuss the twist in economic fortune of the sector as a result of the discovery of oil in commercial quantity in 1968. The paper exposes among other things that despite the humongous amount of wealth that is realized from the sale of crude in the country since that period, about 53 million Nigerians, which represents about $30 \%$ of the nation's population are still undernourished, while about 118.2 million which represents about $72 \%$ of the total population still live below the poverty line. Using qualitative analysis of technique, the paper emphasizes significant improvements and effective harnessing of agricultural sector for meaningful and adequate food production and other socio-economic developments through agricultural reforms. Specifically, the study limits itself to the important role of agricultural transformation in engendering sustainable development and significant levels of hunger and poverty reduction in South Western Nigeria.

\section{Theoretical Framework and Model Specification}

This study adopts the traditional two factor neo-classical theory of production in which land (and perhaps capital) is fixed, labor is the only variable input, and profit is maximized. Specifically, the theory provides an economic rationale for the observed low productivity of traditional agriculture in the form of the law of diminishing marginal productivity ${ }^{2}$. The relevance of this theory is stemmed from the subsistence nature of farming system in Sub-Saharan Africa. Unfortunately, this theory according to Todaro and Smith (2009) does not satisfactorily explain why small-scale farmers are often resistant to technological innovation in farming techniques or to the introduction of new seeds or different cash crops. According to the standard theory, a rational income or profit-maximizing farm or firm will always choose a method of production that will increase output for a given cost (in this case, the available labor time) or lower costs for a given output level. But the

\footnotetext{
${ }^{2}$ An exposition made by Weitz (1971).
} 
theory is based on the crucial assumption that farmers possess "perfect knowledge" of all technological input-output relationships as well as current information about prevailing factor and product prices.

Given the above theoretical background, the study applies the Cobb-Douglas production function in Abiola (2010), where;

$Q=A K^{\alpha} L^{\beta}$

where $\mathrm{Q}=$ the output

$\mathrm{A}=$ Efficiency parameter

$\mathrm{K}=$ Fixed input of Capital

$\mathrm{L}=$ Variable input of Labour

Equation 1 is not a convenient form for direct estimation by least squares methods; it is therefore usually converted into a logarithmic form:

$\log Q=\log A+\alpha \log K+\beta \log L+\mu$

so that the residual $\mu$ is added in the multiplicative form $e^{\mu}$.

A priori expectation suggests that both $\alpha$ and $\beta$ are greater than zero but less that one. That is, $0<\alpha<1$ and $0<\beta<1$. In the case where constant returns to scale is present, then $\alpha+\beta=1$. Alternatively, constant returns to scale may be imposed by putting $\beta=1-\alpha$, so that (1) can be rewritten as:

$$
Q=A K^{\alpha} L^{1-\alpha} e^{\mu} \Rightarrow Q=A\left(\frac{K}{L}\right)^{\alpha} L e^{\mu}
$$

or

$$
\frac{Q}{L}=A\left(\frac{K}{L}\right)^{\alpha} e^{\mu}
$$

and taking logarithms of both sides gives

$$
\log \left(\frac{Q}{L}\right)=\log A+\alpha \log \left(\frac{K}{L}\right)+\mu
$$

This second form avoids multicollinearity between $\log \mathrm{K}$ and $\log \mathrm{L}$ and also reduces heteroscedasticity if the variance of $\mathrm{K}$ is correlated with $\mathrm{L}$ (Wynn and Holden 1974).

Given the generic production function stated in 1 , the model for the study is specified as:

$Q=A X_{1}^{\alpha} X_{2}^{\beta} X_{3}^{\delta} X_{4}^{\lambda} X_{5}^{\sigma} X_{6}^{\pi}$

Where, 
$Q=$ AGDP $=\quad$ Agricultural Gross Domestic Product

$X_{1}=\mathrm{EXPE}=\quad$ Expenditure on Education

$X_{2}=\mathrm{EXPH}=\quad$ Expenditure on Health

$X_{3}=$ EXPEL $=\quad$ Expenditure on Electricity

$X_{4}=$ EXPTC $=\quad$ Expenditure on Telecommunication

$X_{5}=$ EXPRC $=\quad$ Expenditure on Road and Construction

$X_{6}=\mathrm{EXPA}=\quad$ Expenditure on Agriculture

In linear form, this can be expressed as:

$\log Q=\log A+\alpha \log X_{1}+\beta \log X_{2}+\delta \log X_{3}+\lambda \log X_{4}+\sigma \log X_{5}+\pi \log X_{6}+\mu$

\section{Estimation Procedure}

A study of agricultural productivity in economic literature shows that the methodologies adopted range from the descriptive analysis, most of which are qualitative in nature to econometric analyses. The econometric analyses involve the use of ordinary least square (OLS), the co-integration analyses and the error correction model (ECM), the two-stage least square for the ones involving simultaneous equations, the Generalized Method of Moments (GMM) panel estimation for the ones involving panel data, the generalized autoregressive conditional heteroskedasticity $(\mathrm{GARCH})$ and the vector error correction model (VECM).

In spite of the advantages of each method mentioned above, this model has adopted the methodology of Structural Vector Autoregression (SVAR). The advantages of SVAR according Kilian (2011) are classified under four main applications. First, they are used to study the average response of the model variables to a given one-time structural shock. Second, they allow the construction of forecast error variance decompositions that quantify the average contribution of a given structural shock to the variability of the data. Third, they can be used to provide historical decompositions that measure the cumulative contribution of each structural shock to the evolution of each variable over time. Finally, structural VAR models allow the construction of forecast scenarios conditional on hypothetical sequences of future structural shocks.

A typical estimation procedure for SVAR model involves the some steps. First is the examination of the stationarity or otherwise of the time series data included in the model. One important notice is that SVAR models involve high frequency data and as such annual time series data may not adequately capture the kind of expected result. Therefore it is advisable as much as possible that quarterly data of the series included in the model are used rather than the annual series. Where quarterly data are not easily available in some series, this problem may be overcome by disaggregating the data using different types of techniques available in many of the econometric packages. 
The next step involves the estimation of the reduced form VAR, ensuring that adequate length have been taken into consideration. What constitutes adequate lag length can be taken care of by the use of lag length criteria available in econometric packages. Prominent among these lag length criteria are the Akaike, Schwartz and Hannan-Quinn information criteria. According to Gutierrez et al. (2007), an important aspect of empirical research in the specification of the VAR models is the determination of the lag order of the autoregressive lag polynomial, since all inference in the VAR model depends on the correct model specification. In several contributions, the effect of lag length selection has been demonstrated. Lütkepohl (1993) indicates that selecting a higher order lag length than the true lag length causes an increase in the mean square forecast errors of the VAR and that under fitting the lag length often generates autocorrelated errors. Braun and Mittnik (1993) show that impulse response functions and variance decompositions are inconsistently derived from the estimated VAR when the lag length differs from the true lag length. When cointegration restrictions are considered in the model, the effect of lag length selection on the cointegration tests has been demonstrated. For example, Johansen (1991) and Gonzalo (1994) point out that VAR order selection may affect proper inference on cointegrating vectors and rank.

In this study, one broad equation as contained in equation 7 was estimated. The equation that was used to estimate the aggregate agricultural output has seven variables. Q was used to represent agricultural output, APRC represented average price of the aggregate agricultural output, ACR was used to represent acreage while $\mathrm{LAB}$ was used to represent labour force in the agricultural sector. The other variables are as previously defined. Following the Cholesky ordering and based on economic theory; equation 6 can be represented as follows:

\section{$\mathrm{AGDP}=\mathrm{f}(\mathrm{EXPH}, \mathrm{EXPE}, \mathrm{EXPEL}, \mathrm{EXPRC}, \mathrm{EXPTC}, \mathrm{EXPA})$}

Taking a cue from the Structural VAR equations above, $n\left(\frac{n+1}{2}\right)=7\left(\frac{7+1}{2}\right)=28$ restrictions on the model, and hence, $7^{2}-28=21$ more restrictions are required to identify the structural matrix $B$

$$
\tilde{Y}=\left[\begin{array}{lllllll}
b_{11} A G D P & +b_{12} E X P H & +b_{13} E X P E & +b_{14} E X P E L & +b_{15} E X P R C & +b_{16} E X P T C & +b_{17} E X P A \\
b_{21} A G D P & +b_{22} E X P H & +b_{23} E X P E & +b_{24} E X P E L & +b_{25} E X P R C & +b_{26} E X P T C & +b_{27} E X P A \\
b_{31} A G D P & +b_{32} E X P H & +b_{33} E X P E & +b_{34} E X P E L & +b_{35} E X P R C & +b_{36} E X P T C & +b_{37} E X P A \\
b_{41} A G D P & +b_{42} E X P H & +b_{43} E X P E & +b_{44} E X P E L & +b_{45} E X P R C & +b_{46} E X P T C & +b_{47} E X P A \\
b_{51} A G D P & +b_{52} E X P H & +b_{53} E X P E & +b_{54} E X P E L & +b_{55} E X P R C & +b_{56} E X P T C & +b_{57} E X P A \\
b_{61} A G D P & +b_{62} E X P H & +b_{63} E X P E & +b_{64} E X P E L & +b_{65} E X P R C & +b_{66} E X P T C & +b_{67} E X P A \\
b_{71} A G D P & +b_{72} E X P H & +b_{73} E X P E & +b_{74} E X P E L & +b_{75} E X P R C & +b_{76} E X P T C & +b_{17} E X P A
\end{array}\right]
$$

This matrix can be represented as follows: 
$\left[\begin{array}{lllllll}b_{11} & b_{12} & b_{13} & b_{14} & b_{15} & b_{16} & b_{17} \\ b_{21} & b_{22} & b_{23} & b_{24} & b_{25} & b_{26} & b_{27} \\ b_{31} & b_{32} & b_{33} & b_{34} & b_{35} & b_{36} & b_{37} \\ b_{41} & b_{42} & b_{43} & b_{44} & b_{45} & b_{46} & b_{47} \\ b_{51} & b_{52} & b_{53} & b_{54} & b_{55} & b_{56} & b_{57} \\ b_{61} & b_{62} & b_{63} & b_{64} & b_{65} & b_{66} & b_{67} \\ b_{71} & b_{72} & b_{73} & b_{74} & b_{75} & b_{76} & b_{77}\end{array}\right]\left[\begin{array}{c}A G D P \\ E X P H \\ E X P E \\ E X P E L \\ E X P R C \\ E X P T C \\ E X P A\end{array}\right]=\left[\begin{array}{c}\varepsilon_{1} \\ \varepsilon_{2} \\ \varepsilon_{3} \\ \varepsilon_{4} \\ \varepsilon_{5} \\ \varepsilon_{6} \\ \varepsilon_{7}\end{array}\right]$

To arrive at the recursive restriction matrix, the followings restrictions were made to retrieve the structural shocks.

1. Agricultural output (AGDP) is affected by all the variables in the model. This is in consonance with the production function specified in equation 6 .

2. Expenditure on health (EXPH) is affected by expenditure on education (EXPE). They are both variables of human capital development. These variables, if present at the rural areas are capable of stemming the ruralurban influx.

3. The expenditure on education (EXPE) is affected by only EXPH. The reason as stated in 2 .

4. Expenditure on electricity (EXPEL) is affected by expenditure on road and construction (EXPRC) and expenditure on telecommunication (EXPTC). They are both variables of social amenities, the presence of which makes life comfortable for rural dwellers and debar them from moving en-masse to the cities.

5. Expenditure on road and construction (EXPRC) is affected by expenditure on electricity (EXPEL) and expenditure on telecommunication (EXPTC). Reason as stated in 4.

6. Expenditure on telecommunication (EXPTC) is affected by expenditure on road and construction (EXPRC) and expenditure on electricity (EXPEL).

7. Expenditure on agriculture is affected by all the other variables with the exception of agricultural gross domestic product.

From the assumptions above, the following are applicable. In the case of EXPE and EXPH, that are assumed to be affected by one and other, $\mathrm{b}_{21}=\mathrm{b}_{24}=\mathrm{b}_{25}=\mathrm{b}_{26}=\mathrm{b}_{27}=\mathrm{b}_{31}=\mathrm{b}_{34}=\mathrm{b}_{35}=\mathrm{b}_{36}=\mathrm{b}_{37}=0$. On the restriction placed on EXPEL, EXPRC and EXPTC the implication is that other variables of AGDP, EXPH, EXPE and EXPA do not affect them. Therefore, $b_{41}=b_{42}=b_{43}=b_{47}=b_{51}=$ $b_{52}=b_{53}=b_{57}=b_{61}=b_{62}=b_{63}=b_{67}=0$. Expenditure on agriculture (EXPA) is affected all other variables with the exception of agricultural gross domestic product, therefore $b_{71}=0$. Based on these restrictions, the resultant recursive matrix is presented thus: 
Vol. 8, No. 2 Abiola \& Adefabi: Rural Structural Transformation and Agricultural...

$$
B_{0}=\left[\begin{array}{ccccccc}
b_{11} & b_{12} & b_{13} & b_{14} & b_{15} & b_{16} & b_{17} \\
0 & b_{22} & b_{23} & 0 & 0 & 0 & 0 \\
0 & b_{32} & b_{33} & 0 & 0 & 0 & 0 \\
0 & b_{42} & b_{43} & b_{44} & 0 & 0 & 0 \\
0 & b_{52} & b_{53} & b_{54} & 0 & 0 & 0 \\
0 & b_{62} & b_{63} & b_{64} & 0 & 0 & 0 \\
0 & b_{72} & b_{73} & b_{74} & b_{75} & b_{76} & b_{77}
\end{array}\right]
$$

Expressing the restrictions in linear form, we have:

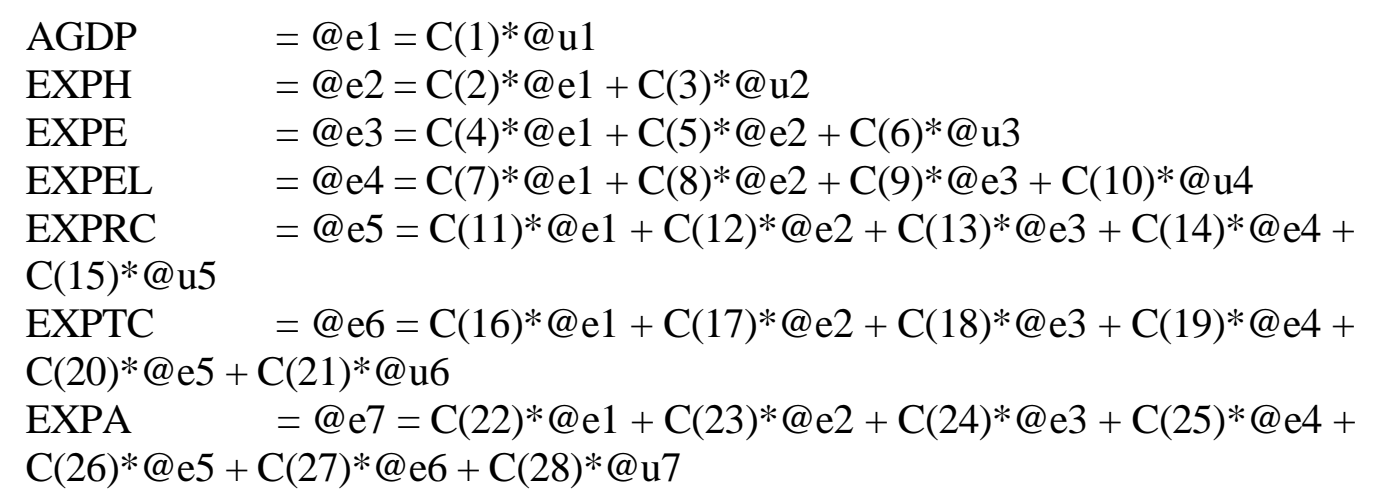

\section{Results and Discussion}

Table 1 presents the statistical properties of the series used for the models. The table provides information about the mean, the median, standard deviation, the maximum value, the minimum value, the skewness as well as the Jarque-Bera of each variable. The table shows the logarithm of the observed value of each variable. The mean values of the logarithm of agricultural gross domestic product (AGDP) and that of expenditure on education (EXPE) are 1.47 and 1.37 respectively. The implication of this is that of the other variables under consideration, the observed data of both the AGDP and EXPE appears to have biggest values throughout the period of observation. Expenditures on agriculture and telecommunication have the lowest means of 1.33 each. This is implies that both AGDP and EXPE have the lowest observed value in the series that make up the model. One important statistical characteristic of the variables in Table 1 is the near equality of both the mean and the median for all the variables. This implies a near perfect normal distribution data sets, a common assumption underlying many statistical tests. 
Table 1. Summary Statistics of the Series

\begin{tabular}{|l|c|c|c|c|c|c|c|}
\hline & AGDP & EXPA & EXPE & EXPEL & EXPH & EXPRC & EXPTC \\
\hline Mean & 1.47 & 1.33 & 1.37 & 1.35 & 1.35 & 1.35 & 1.33 \\
\hline Median & 1.47 & 1.36 & 1.39 & 1.36 & 1.37 & 1.36 & 1.35 \\
\hline Maximum & 1.48 & 1.40 & 1.43 & 1.42 & 1.42 & 1.41 & 1.40 \\
\hline Minimum & 1.45 & 1.21 & 1.28 & 1.24 & 1.24 & 1.26 & 1.24 \\
\hline Std. Dev. & 0.01 & 0.06 & 0.05 & 0.06 & 0.06 & 0.05 & 0.05 \\
\hline Skewness & 0.17 & -0.74 & -0.56 & -0.30 & -0.42 & -0.24 & -0.56 \\
\hline Kurtosis & 1.50 & 2.11 & 1.88 & 1.85 & 1.70 & 1.71 & 1.96 \\
\hline Jarque-Bera & 14.70 & 18.45 & 15.69 & 10.52 & 14.77 & 11.76 & 14.57 \\
\hline Probability & 0.00 & 0.00 & 0.00 & 0.01 & 0.00 & 0.00 & 0.00 \\
\hline Sum & 218.86 & 198.14 & 203.87 & 200.45 & 201.52 & 200.75 & 198.60 \\
\hline Sum Sq. Dev. & 0.01 & 0.55 & 0.40 & 0.53 & 0.47 & 0.35 & 0.39 \\
\hline Observations & 149 & 149 & 149 & 149 & 149 & 149 & 149 \\
\hline
\end{tabular}

Source: Author's Computation from E-Views 9. Data source: CBN 2018.

\section{Correlation}

Table 2 displays correlations between logarithm of agricultural gross domestic product (AGDP) and its determinants. This was done to avoid inconsistency in the regression analysis by establishing the substitutability of the variables. As a result, they provide a useful guide in the specification of the models. The simple correlations suggest that there was a positive correlation between logarithm of AGDP and the logarithm of all the determinants with the exception of that of inflation rate. In all the cases, the correlation appears to be strong, as the coefficients of the correlation are more than $80 \%$.

Table 2. Correlations

\begin{tabular}{|l|c|c|c|c|c|c|c|}
\hline & AGDP & EXPA & EXPE & EXPEL & EXPH & EXPRC & EXPTC \\
\hline AGDP & 1.00 & 0.89 & 0.93 & 0.95 & 0.95 & 0.97 & 0.90 \\
\hline EXPA & 0.89 & 1.00 & 0.98 & 0.96 & 0.97 & 0.97 & 0.98 \\
\hline EXPE & 0.93 & 0.98 & 1.00 & 0.97 & 0.99 & 0.97 & 0.96 \\
\hline EXPEL & 0.95 & 0.96 & 0.97 & 1.00 & 0.98 & 0.98 & 0.95 \\
\hline EXPH & 0.95 & 0.97 & 0.99 & 0.98 & 1.00 & 0.97 & 0.96 \\
\hline EXPRC & 0.97 & 0.97 & 0.97 & 0.98 & 0.97 & 1.00 & 0.96 \\
\hline EXPTC & 0.90 & 0.98 & 0.96 & 0.95 & 0.96 & 0.96 & 1.00 \\
\hline
\end{tabular}

Source: Author's Computation from E-Views 9 Data source: CBN 2018.

\section{Stationarity Property of the Series}

The data used for the analysis is time series. The major problem associated with that type of data is the serial or autocorrelation problem. If this problem is not taken care of, the results obtained from it will be spurious or nonsense. Testing for the stationarity or otherwise of a series involves testing for the unit root. This study tested for unit root using the Augmented Dickey Fuller approach. 
Table 3. Augmented Dickey Fuller Unit Root Test

\begin{tabular}{|l|c|c|c|c|}
\hline Variables & Level & $\mathbf{1}^{\text {st }}$ Difference & $\mathbf{2}^{\text {nd }}$ Difference & $\begin{array}{c}\text { Order of } \\
\text { Integration }\end{array}$ \\
\hline AGDP & -0.7361 & $-3.0857^{* *}$ & & $\mathrm{I}(1)$ \\
\hline EXPE & -1.5127 & $-4.4779^{*}$ & & $\mathrm{I}(1)$ \\
\hline EXPH & -1.3804 & $-4.1320^{*}$ & & $\mathrm{I}(1)$ \\
\hline EXPEL & -1.3551 & $-3.3491^{* *}$ & & $\mathrm{I}(1)$ \\
\hline EXPTC & -1.7160 & $-4.3938^{*}$ & & $\mathrm{I}(1)$ \\
\hline EXPRC & -1.9660 & $-3.4076^{* *}$ & & $\mathrm{I}(1)$ \\
\hline EXPA & -2.3724 & $-3.2283^{* *}$ & & $\mathrm{I}(1)$ \\
\hline
\end{tabular}

Critical Statistics: $1 \%=-3.4778,5 \%=-2.8823,10 \%=-2.5779$

*Significant@1\%,**Significant@5\%,***Significant@10\%

Source: Author's Computation from E-Views 9 Data source: CBN 2018.

Table 3 shows the unit root test results using Augmented Dickey Fuller (intercept) approach. From the results all the series that make up the model were non stationary. To make them stationary, they were all made stationary after first differencing. Since the stationary properties of the series had been determined, we proceeded to estimate the Vector Autoregression by first examining the lag length needed for the estimation. The results are presented in Table 4.

Table 4. Lag Selection Criteria

\begin{tabular}{|c|c|c|c|c|c|c|}
\hline & & VAR Las & Order Selec & tion Criteria & & \\
\hline Endoge & us variables: & AGDP EXP & EXPE EXP & EL EXPH EX & PRC EXPTC & \\
\hline Exogen & S variables: & & & & & \\
\hline Sample & 9812018 & & & & & \\
\hline Include & bservations: & & & & & \\
\hline Lag & $\log L$ & LR & FPE & AIC & SC & HQ \\
\hline 0 & 786.1064 & NA & $3.76 \mathrm{e}-28$ & -43.28369 & -42.97578 & -43.17622 \\
\hline 1 & 934.5866 & 230.9692 & $1.58 \mathrm{e}-30$ & -48.81037 & $-46.34711 *$ & -47.95063 \\
\hline 2 & 1015.171 & $94.01487 *$ & $3.77 \mathrm{e}-31 *$ & $-50.56504 *$ & -45.94645 & $-48.95303^{*}$ \\
\hline$*$ indic & s lag order $\mathrm{s}$ & lected by the & riterion & & & \\
\hline LR: sec & ential modifi & d LR test sta & stic (each tes & $t$ at 5\% level) & & \\
\hline FPE: F & l prediction & error & & & & \\
\hline AIC: A & ike informat & on criterion & & & & \\
\hline SC: $\mathrm{Sc}$ & arz informa & on criterion & & & & \\
\hline HQ: $\mathrm{H}$ & an-Quinn in & formation c & & & & \\
\hline
\end{tabular}

The results above show that of the five criteria available for choosing the lag length, four chose lag length 2. This forms the basis for the estimation of our Vector Autoregression. 
Table 5. Structural VAR Estimates of the Foreign Direct Investment Equation

\begin{tabular}{|c|c|c|c|c|}
\hline & Coefficient & Std. Error & z-Statistic & Prob. \\
\hline $\mathbf{C}(\mathbf{1})$ & 0.000937 & 0.000110 & 8.485281 & 0.0000 \\
\hline $\mathrm{C}(2)$ & 0.776511 & 2.460008 & 0.315654 & 0.7523 \\
\hline $\mathrm{C}(3)$ & 0.013827 & 0.001630 & 8.485281 & 0.0000 \\
\hline C(4) & 3.380533 & 1.788611 & 1.890033 & 0.0588 \\
\hline $\mathrm{C}(5)$ & 0.395911 & 0.121012 & 3.271674 & 0.0011 \\
\hline $\mathrm{C}(6)$ & 0.010040 & 0.001183 & 8.485281 & 0.0000 \\
\hline $\mathbf{C}(7)$ & -0.094106 & 1.294108 & -0.072718 & 0.9420 \\
\hline $\mathrm{C}(\mathbf{8})$ & -0.020724 & 0.095118 & -0.217873 & 0.8275 \\
\hline $\mathrm{C}(9)$ & 0.222752 & 0.115016 & 1.936702 & 0.0528 \\
\hline $\mathrm{C}(10)$ & 0.006928 & 0.000817 & 8.485281 & 0.0000 \\
\hline $\mathrm{C}(11)$ & 2.544275 & 0.969888 & 2.623266 & 0.0087 \\
\hline $\mathrm{C}(12)$ & -0.104364 & 0.071329 & -1.463124 & 0.1434 \\
\hline $\mathrm{C}(13)$ & 0.809631 & 0.090573 & 8.938959 & 0.0000 \\
\hline $\mathrm{C}(14)$ & 0.305774 & 0.124902 & 2.448116 & 0.0144 \\
\hline $\mathrm{C}(15)$ & 0.005192 & 0.000612 & 8.485281 & 0.0000 \\
\hline $\mathrm{C}(16)$ & 2.308275 & 1.341442 & 1.720741 & 0.0853 \\
\hline $\mathbf{C}(17)$ & 0.587530 & 0.093042 & 6.314680 & 0.0000 \\
\hline $\mathbf{C}(18)$ & -0.033960 & 0.205952 & -0.164894 & 0.8690 \\
\hline $\mathbf{C}(19)$ & 0.185460 & 0.170952 & 1.084869 & 0.2780 \\
\hline $\mathrm{C}(20)$ & -0.251444 & 0.211210 & -1.190491 & 0.2339 \\
\hline $\mathrm{C}(21)$ & 0.006580 & 0.000775 & 8.485281 & 0.0000 \\
\hline $\mathrm{C}(22)$ & 3.570696 & 1.250473 & 2.855477 & 0.0043 \\
\hline $\mathbf{C}(23)$ & 0.123914 & 0.121036 & 1.023776 & 0.3059 \\
\hline $\mathrm{C}(24)$ & 0.214564 & 0.184616 & 1.162218 & 0.2451 \\
\hline $\mathrm{C}(25)$ & -0.384104 & 0.155667 & -2.467469 & 0.0136 \\
\hline $\mathrm{C}(26)$ & -0.223016 & 0.192947 & -1.155841 & 0.2477 \\
\hline $\mathbf{C}(27)$ & 0.489251 & 0.149344 & 3.276000 & 0.0011 \\
\hline $\mathrm{C}(28)$ & 0.005896 & 0.000695 & 8.485281 & 0.0000 \\
\hline
\end{tabular}

Source: Author's Computation from E-Views 9. Data source: CBN 2018.

Table 5 displays the estimates of the SVAR model for the determinants of agricultural productivity on the basis of rural structural transformation in Nigeria. These were the results of the model specified and estimated with the objective of investigating the impact of the expenditure on rural structural transformation on agricultural productivity in Nigeria. The 28 coefficients gave an insightful depiction of the kind of cross relationships among the variables that make up the model. The coefficients of major concern to this analysis are $\mathrm{C}(2), \mathrm{C}(3), \mathrm{C}(4)$, $\mathrm{C}(5), \mathrm{C}(6)$ and $\mathrm{C}(7)$. These are the coefficients of expenditures on education (EXPE), health (EXPH), electricity (EXPEL), telecommunication (EXPTC), road and construction (EXPRC) and agriculture (EXPA). All the variables were found to be positively related to agricultural productivity with the exception of the coefficient 7 , the coefficient associated with agriculture. The implication of the results is that they all follow the a priori expectation with the exception of agriculture which was found to be negative as against the expected positive relation. The results however is a manifestation of sharp practices from those in 
charge of funds relating to agricultural sector. This mostly as it concerns the diversion of funds for agricultural development for personal uses, engaging in the sales of fertilizers meant for distribution to farmers and a lot of corrupt practices among high level personnel handling agricultural issues in the country. The impulse response function of the SVAR is presented in Figure 1.

Figure 1. Agricultural Productivity Impulse Response Function

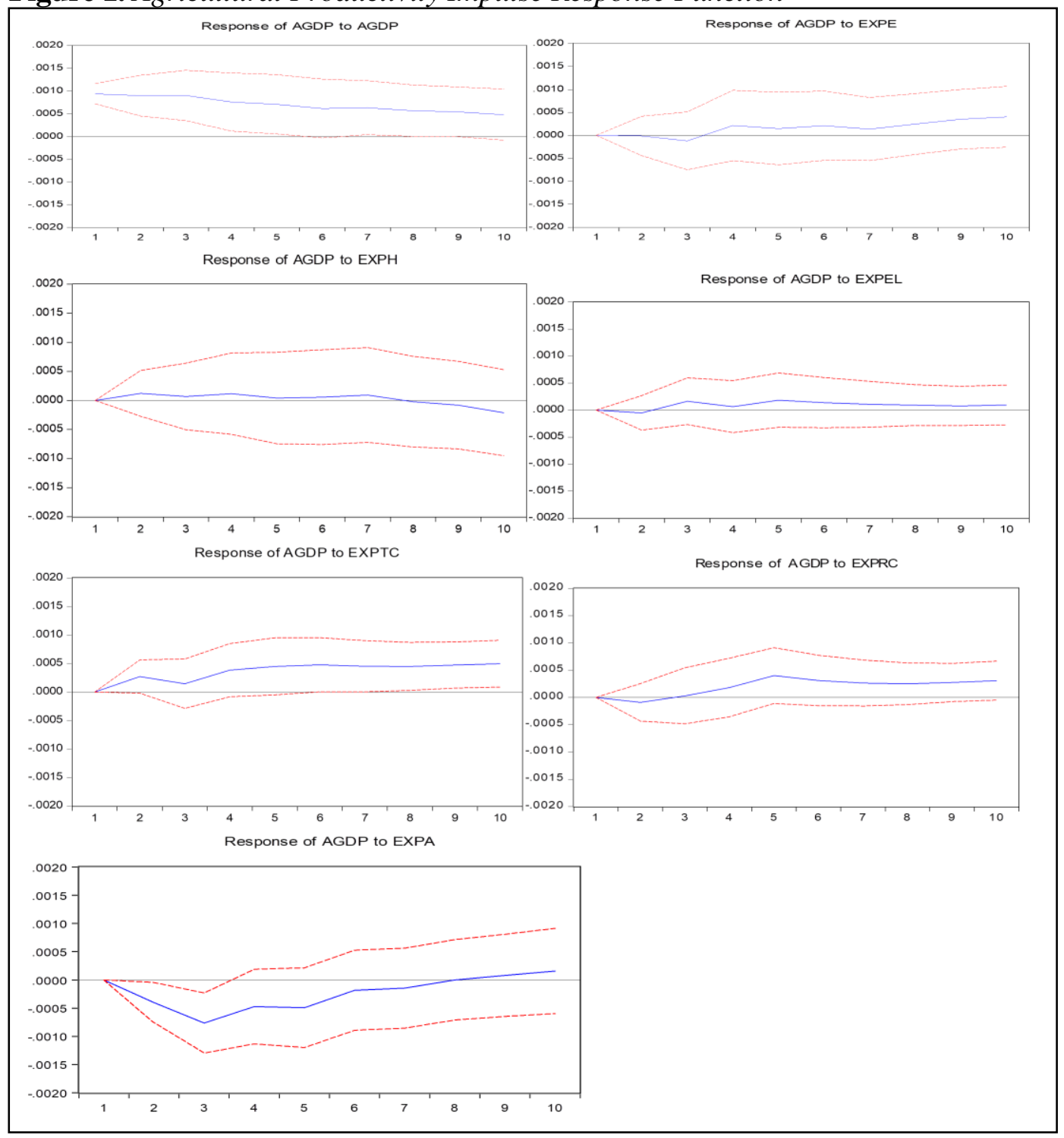

The first figure of Figure 1 shows the response of AGDP to its own shock. A one standard deviation shock to AGDP led to a rise in AGDP from period one all through to period ten, albeit positive movement. The second figure (north-east corner) shows the response of AGDP to the shock from expenditure on inflation. With an impulse from expenditure on education, the AGDP was unresponsive from period one to two, before a positive response was observed from period two to ten. The positive trend responsive was similar for expenditure on health, 
electricity, telecommunication and road and construction. In the case of impulse from agriculture, the response of AGDP was negative from period one to 8, before a positive response was observed for periods 8 to 10 .

Table 6. Variance Decomposition of AGDP

\begin{tabular}{|l|c|c|c|c|c|c|c|c|}
\hline \multicolumn{7}{|c|}{ Variance Decomposition of AGDP } \\
\hline Period & S.E. & AGDP & EXPA & EXPE & EXPEL & EXPH & EXPRC & EXPTC \\
\hline $\mathbf{1}$ & 0.000937 & 100.0000 & 0.000000 & 0.000000 & 0.000000 & 0.000000 & 0.000000 & 0.000000 \\
\hline $\mathbf{2}$ & 0.001394 & 86.56125 & 1.421501 & 0.291091 & 0.003920 & 0.431917 & 5.963038 & 5.327285 \\
\hline $\mathbf{3}$ & 0.001846 & 73.12613 & 6.096622 & 0.424673 & 0.789201 & 0.526256 & 14.68152 & 4.355593 \\
\hline $\mathbf{4}$ & 0.002108 & 68.89497 & 4.772531 & 1.301817 & 0.835168 & 0.537266 & 19.15342 & 4.504831 \\
\hline $\mathbf{5}$ & 0.002367 & 63.53720 & 4.243597 & 1.149540 & 1.311566 & 0.426677 & 25.46160 & 3.869825 \\
\hline $\mathbf{6}$ & 0.002530 & 61.47988 & 5.557273 & 1.048348 & 1.544535 & 0.449193 & 26.13886 & 3.781908 \\
\hline $\mathbf{7}$ & 0.002671 & 60.74969 & 6.172287 & 0.941013 & 1.676605 & 0.580307 & 26.10150 & 3.778594 \\
\hline $\mathbf{8}$ & 0.002790 & 59.77258 & 8.181866 & 0.880339 & 1.642435 & 0.548168 & 25.23365 & 3.740961 \\
\hline $\mathbf{9}$ & 0.002918 & 58.07223 & 11.33034 & 0.892784 & 1.540136 & 0.501565 & 24.02397 & 3.638977 \\
\hline $\mathbf{1 0}$ & 0.003053 & 55.49299 & 15.50192 & 0.886023 & 1.416573 & 0.561579 & 22.67054 & 3.470373 \\
\hline
\end{tabular}

Source: Author's Computation. Data source: CBN 2018.

Table 6 shows the results of variance decomposition of the first ten periods' horizon into the future. The results show that in the first period, variations in AGDP were wholly explained by own shocks. This implies that variations in AGDP were hardly affected by other variables in the first period. The results also show that beside own contribution, variations in AGDP was mainly attributed to expenditure on agriculture, road and construction as well as expenditure on telecommunication. The expenditures on other social amenities like health, electricity and education marginally attribute to changes in variations in agricultural gross domestic product. Expenditures on agriculture and road and construction that contribute mostly to agricultural productivity accounted $1.4 \%$ and $6.0 \%$ respectively in period 1 , and by period 10 , it had risen to $15.5 \%$ and $22.7 \%$ respectively.

\section{Conclusion}

From the above analysis, it is confirmed that along the line of rural structural transformation, expenditures on social amenities plays very important roles. These social amenities are indirectly related to agricultural productivity in the country. Of the push factors that draw away productive agricultural labour force from the rural areas to urban areas are the absence of basic social facilities that can make life comfortable for the rural dwellers. Transforming rural area structurally entails the provision of these facilities. This study therefore made use of six explanatory variables of rural structural transformation to explain agricultural productivity in Nigeria. Of the six variables, expenditures on education, health, electricity, road and construction and telecommunication were found to be positively related to agricultural productivity, while expenditure on agriculture was found to be negatively related to its productivity. Although the relationship between expenditure on agriculture and its productivity was negative, the results of the 
variance decomposition shows that the variable has the strongest impact on agricultural productivity than any of the other variables under consideration.

\section{Recommendations}

On the bases of the above analysis and findings, it is highly recommended that government should expend more on those social and basic amenities for people of rural areas, so as to act as motivation and incentives for them to staying in the rural villages and make career out of the farming profession. New roads should be constructed for them, existing ones to be rehabilitated so that it will be motorable for the rural dwellers to transport themselves as well as their goods. Electricity should be provided to have a feel of life in the cities. Internet facilities should be made available for them to get themselves acquainted with happenings in the world and be educated about the current methods of agricultural production. Hospitals, clinic and maternity centres should be provided to improve on their health status, while schools should be provided to at least cater for their basic educational needs. All these when provided, will act as impetus for the rural farmers to be more productive and this will ultimately lead to improve agricultural productivity in the country.

\section{References}

Abiola A (2010) Capital-labour substitution and banking sector performance in Nigeria (1960-2008), Central Bank of Nigeria, Economic and Financial Review 48(2): 109130

Abiola A (2017) Agricultural supply response to trade and exchange rate reforms in Nigeria. Unpublished $\mathrm{PhD}$ Thesis. Ibadan, Nigeria: Department of Economics, University of Ibadan.

Adeyinka A, Salau S, Vollrath D (2013) Structural change in the Nigerian economy. Working Paper 24. International Food Policy Research Institute.

Adikwu S E (2016) The need for agricultural transformation. The Sun Newspaper, May 31.

Alvarez-Cuadrado F, Poschke M (2009) Structural change out of agriculture, labour push versus labour pull. Discussion Paper 4247. Germany: Institute for the Study of Labour (IZA).

Barrett CB, Christiaensen L, Sheahan M, Shimeless A (2017) On the structural transformation of rural Africa. Journal of African Economies 26(1): 11-35.

Braun PA, Mittnik S (1993) Misspecifications in vector autoregressions and their effects on impulse responses and variance decompositions. Journal of Econometrics 59(3): 319-341.

Briones R, Felipe J (2014) Agriculture and structural transformation in developing Asia: review and outlook. Working Paper Series 363. Asian Development Bank Economics.

Central Bank of Nigeria - CBN (2018) Statistical bulletin. CBN. Retrieved from: www. cbn.gov.ng/documents/Statbulletin.asp. [Accessed 8 February 2021] 
Diao X (2010) Economic importance of agriculture for sustainable development and poverty reduction: findings from a case study of Ghana. In Global Forum on Agriculture. November 29-30. Paris: OECD.

Eboh EC (2014) Agricultural economics of Nigeria: paradoxes and crossroads of multimodal nature. Nsukka: University of Nigeria.

Food and Agricultural Organisation - FAO (2011) The future of food and agriculture. Retrieved from: http://www.fao.org/3/i6583e/i6583e.pdf. [Accessed 8 February 2021]

Gangopadhyay K, Mondal D (2017) Agricultural productivity and structural change: a falsifiable approach to explain structural break in relative price of manufacturing. Indian Institute of Management.

Gonzalo J (1994) Five alternative methods of estimating long run equilibrium relationships. Journal of Econometrics 60(1-2): 203-233.

Gutierrez CEC, Souza RC, Gullen OT (2007) Selection of optimal lag length in cointegrated var models with weak form of common cyclical features. Working Paper 139. Banco Central Do Brasil.

Johansen S (1991) Estimation and hypothesis testing of cointegration vectors in guassian vector autoregresive models. Economtrica 59(6): 1551-1580.

Kendrick JW (1977) Understanding productivity: an introduction to the dynamic of productivity change. Baltimore: The John Hopkins University, Press.

Kilian L (2011) Structural vector autoregressions. Mimeo, University of Michigan.

Lopes C 2015 Agriculture as part of Africa's structural transformation, Journal of African Transformation 1(1): 43-61.

Losch B, Freguin-Gresh S, White EC (2012) Structural transformation and rural change revisited. Agence Francaise de Developpement and the World Bank.

Lutkepohl H (1993) Introduction to multiple time series analysis. New York: Springer.

Naseem A, Oehmke JF, Anderson J, Mbaye S, Pray C, Nagarajar L et al. (2017) Measuring agricultural and structural transformation. In 2017 Agricultural and Applied Economics Association Annual Meeting. Chicago, Illinois.

Nwankpa NN (2017) Sustainable agricultural development in Nigeria: a way out of hunger and poverty. European Journal of Sustainable Development 6(4): 175-184.

Oboh VU, Adeleke AI (2016) Accelerating inclusive agricultural growth in Nigeria: an examination of strategic issues, challenges and policy options. International Journal of Development and Economic Sustainability 4(6): 1-25.

Ogbe A (2018) Nigeria must mainstream food security in its agricultural production. Federal Ministry of Agriculture and Rural Development.

Omano S, Benfica R, Brooks K, Suttie D (2016) Structural and rural transformation in Africa: challenges, opportunities and implications for policy and investments. Rural Development Report's Africa Chapter on Inclusive Rural Transformation. IFAD.

Timmer CP, Akkus S (2008) The structural transformation as a pathway out of poverty: analytics, empirics and politics. Working Paper 150. Centre for Global Development.

Todaro MP, Smith SC (2009) Economic development. $10^{\text {th }}$ Edition. USA: Addison Wesley Publishing.

Weitz R (1971) From peasant to farmer: a revolutionary strategy for development. New York: Columbia University Press.

World Bank (2018) Indicators. Retrieved from: https://data.worldbank.org/indicator. [Accessed 8 February 2021]

Wynn RF, Holden K (1974) An introduction to applied econometric analysis. New York: Macmillian Publications.

Yakubu M, Akanegbu B (2015) Neglecting agriculture and its consequences to the Nigerian economy: an analytical synthesis. European Journal of Research in Social Sciences 3(3): 18-27. 
